Pesq. Vet. Bras. 36(1):24-28, janeiro 2016

DOI: $10.1590 / \mathrm{S} 0100-736 \mathrm{X} 2016000100004$

\title{
Teores de cobre, zinco e ferro no fígado de búfalos (Bubalus bubalis) com paratuberculose ${ }^{1}$
}

\author{
Alessandra S. Belo Reis ${ }^{2}$, Marilene F. Brito ${ }^{3}$, Henrique A. Bomjardim ${ }^{2}$, Kelson C.F. Faial ${ }^{4}$, \\ Felipe M. Salvarani ${ }^{2}$, Daniel G. Ubiali ${ }^{3}$, Carlos Magno C. Oliveira ${ }^{2}$ e José D. Barbosa ${ }^{2 *}$
}

\begin{abstract}
Belo Reis A.S., Brito M.F., Bomjardim H.A., Faial K.C.F., Salvarani F.M., Ubiali D.G., Oliveira C.M.C. \& Barbosa J.D. 2016. [Copper, zinc and iron content in the liver of buffaloes (Bubalus bubalis) with paratuberculosis.] Teores de cobre, zinco e ferro no fígado de búfalos (Bubalus bubalis) com paratuberculose. Pesquisa Veterinária Brasileira 36(1):24-28. Instituto de Medicina Veterinária, Campus de Castanhal, Universidade Federal do Pará, Rodovia BR-316 Km 61, Castanhal, PA 68741-740, Brazil. E-mail: diomedes@ufpa.com

In order to study copper, zinc and iron concentration in the liver of buffaloes with paratuberculosis (PTB), 13 buffalo cows above three years of age of the Murrah and Mediterranean races or their crosses were used. They originated from two farms in the municipalities of São Luís and São Mateus, state of Maranhão, Brazil. The animals were selected according to clinical signs of paratuberculosis, as diarrhea, dehydration and submandibular edema. Rectal biopsies for detection of Mycobacterium avium subsp. paratuberculosis (Map) through PCR in real time (qPCR) and Ziehl-Neelsen (ZN) stain were performed on all animals. Seven buffaloes revealed positive and six were negative for PTB. They were separated into two groups: Group 1 contained seven buffaloes positive for paratuberculosis, and Group 2 contained six animals negative for paratuberculosis. They were euthanized and postmortem examination was performed for the collection of various tissue samples to be fixed in $10 \%$ formalin for histopathology; also liver tissue samples were collected to be frozen for chemical analysis of trace minerals ( $\mathrm{Cu}, \mathrm{Zn}$ and $\mathrm{Fe}$ ). Postmortem showed that all buffaloes with PTB had brown colored mesenteric lymphnodes, indicating hemosiderosis. One buffalo had brown spots on the mucosa of the small intestine. Histopathology revealed moderate to severe hemosiderosis of the spleen in buffaloes of Group 1. All animals positive for PTB showed micromineral levels below the reference values. The average $\mathrm{Cu}$ concentration in buffaloes with PTB was only 18.0ppm and the one of Zn only 68.6ppm. In Group 2, negative for PTB, the average $\mathrm{Cu}$ concentration was $113.7 \mathrm{ppm}$ and the one of $\mathrm{Zn} 110.0 \mathrm{ppm}$. Fe concentrations in buffaloes of both groups were high $(>669 \mathrm{ppm})$. The analysis of trace elements in the liver confirmed copper deficiency, but also showed low levels of zinc and high levels of iron. Based on clinical and pathological findings, and the micromineral concentrations found in the liver, it is concluded that paratuberculosis could lead to mineral deficiency and worsen the clinical condition of the buffaloes.
\end{abstract}

INDEX TERMS: Trace elements, copper, zinc, iron, paratuberculosis, buffaloes, Brazil.

\footnotetext{
${ }^{1}$ Recebido em 26 de maio de 2015.

Aceito para publicação em 25 de janeiro de 2016.

${ }^{2}$ Instituto de Medicina Veterinária, Universidade Federal do Pará, Rodovia BR-316 Km 61, Bairro Saudade, Castanhal, PA 68740-970, Brasil. *Autor para correspondência: diomedes@ufpa.com

${ }^{3}$ Departamento de Epidemiologia e Saúde Pública, Instituto de Vete-rinária, Universidade Federal Rural do Rio de Janeiro (UFRRJ), Seropédica, RJ 23890-000, Brasil.

${ }^{4}$ Laboratório de Toxicologia "Edilson Brabo", Seção de Meio Ambiente (SAMAM), Instituto Evandro Chagas, Rodovia BR-316 Km 7, Levilândia, Ananindeua, PA 67030-000, Brasil.
}

RESUMO.- Com o objetivo de realizar um estudo dos teores de cobre $(\mathrm{Cu})$, zinco $(\mathrm{Zn})$ e ferro $(\mathrm{Fe})$ em búfalas com paratuberculose (PTB) foram utilizadas 13 búfalas, das raças Murrah, Mediterrâneo e seus mestiços acima de três anos de idade, pertencentes a duas propriedades localizadas nos municípios de São Luiz e São Mateus, no Estado do Maranhão. Os animais foram selecionados de acordo com a presença de sinais clínicos sugestivos de paratuberculose, caracterizados por estado nutricional regular a ruim, diarreia crônica líquida a semi-líquida, desidratação, edema submandibular, anestro 
prolongado, mastites e verminose gastrintestinal. Foi realizada biópsia retal em todos os animais, para detecção de $M y c o-$ bacterium avium subsp. paratuberculosis (Map) por meio da qPCR, e exames histopatológicos (HE e Ziehl-Neelsen). No Grupo1 sete animais foram positivos para presença de Map, e no Grupo 2 seis foram negativos. Todos os búfalos foram eutanasiados e necropsiados para coleta de diversos tecidos. Parte dos fragmentos foram fixados em formol a 10\% para histopatologia e fragmentos de tecido hepático foram congelados para as dosagens dos microminerais ( $\mathrm{Cu}, \mathrm{Zn}$ e Fe). À necropsia todos os animais positivos para PTB apresentavam linfonodos mesentéricos de coloração castanha sugestiva de hemossiderose. Adicionalmente, em um animal foram observados pequenos pontos de cor marrom distribuídos difusamente na mucosa do intestino delgado. Na histopatologia foi observada hemossiderose moderada a acentuada no baço dos animais do Grupo 1. Na dosagem dos microminerais todos os animais com PTB apresentaram níveis abaixo dos valores de referência para $\mathrm{Cu}$ e $\mathrm{Zn}$. Observou-se que a média dos teores de $\mathrm{Cu}$ dos búfalos com PTB foi 18,0ppm e de Zn 68,6ppm. No Grupo 2 a média dos teores de $\mathrm{Cu}$ foi 113,7ppm e de Zn 110,0ppm. Os teores de Fe em ambos os grupos foram elevados (>670ppm). Baseado nos achados clínico-patológicos e nas dosagens de minerais realizadas neste estudo, conclui-se que na região estudada, a PTB agravou o quadro clínico de animais com deficiência de $\mathrm{Cu}$ e Zn. Em áreas menos deficientes desses minerais sugere-se que a doença seja capaz de induzir quadros de deficiência mineral secundária.

TERMOS DE INDEXAÇÃO: Microelementos, cobre, zinco, ferro, paratuberculose, bubalinos, Brasil.

\section{INTRODUÇÃO}

Paratuberculose ou doença de Johne é causada por $M y c o-$ bacterium avium subsp. paratuberculosis (Map), bacilo álcool-ácido resistente (BAAR) que acomete mamíferos, principalmente ruminantes domésticos e selvagens. A enfermidade é caracterizada por uma enterite granulomatosa, infecciosa e crônica; a infecção se dá pela ingestão de colostro, leite ou água contaminados com fezes (Chiodini et al. 1984, Mota et al. 2010).

Em casos de paratuberculose (PTB) ocorre diarreia em função da enterite granulomatosa e má absorção de nutrientes (Chiodini et al. 1984), o que justifica a perda progressiva de peso e o mau estado corporal dos animais afetados, que podem gerar perdas econômicas importantes, em função da redução da conversão alimentar, diminuição da produtividade, redução dos níveis de proteína e gordura no leite, perda de peso ao abate, alta incidência de mastite e diminuição da fertilidade (Clarke 1997, Yamasaki et al. 2010).

Os minerais são nutrientes importantes que participam de várias vias metabólicas e exercem funções importantes na reprodução, manutenção do crescimento, metabolismo energético, resposta imune, entre outras atividades metabólicas necessárias ao desempenho produtivo dos animais (Wilde 2006, Lamb et al. 2008).

Paolicchi et al. (2013) realizaram estudo com amostras de soro bovino e observaram relação entre a deficiência de selênio com a infecção por Map. Os autores também cons- tataram que um aumento de $10 \mathrm{ppm}$ de ferro no solo pode estar associado com o aumento no número de animais soropositivos para PTB. Lungton (2004) fez um paralelo entre a PTB e as deficiências de macro e microminerais, e inferiram que quadros graves da doença estão relacionados com as deficiências minerais, atentando para a necessidade de mais estudos dentro dessa linha de pesquisa. 0 objetivo deste trabalho foi realizar um estudo dos teores de cobre, zinco e ferro em búfalos positivos para PTB no estado do Maranhão.

\section{MATERIAL E MÉTODOS}

O estudo foi conduzido em duas propriedades de criação de bubalinos localizadas nos municípios de São Mateus e São Luís, região nordeste do estado do Maranhão, onde já existiam casos de paratuberculose (Belo-Reis et al. 2015). Os históricos foram coletados junto aos proprietários, durante as visitas.

Animais e coleta das amostras. Foram utilizadas 13 búfalas das raças Murrah, Mediterrâneo e seus mestiços, com idades acima de três anos, criadas em sistema extensivo e em pastagens nativas e de Brachiaria spp. (Sinonímia Urochloa). A suplementação do rebanho era realizada através de um suplemento protéicoenergético comercial (durante o período seco do ano) contendo proteína bruta $(350 \mathrm{~g} / \mathrm{kg}), \mathrm{NNP}(297 \mathrm{~g} / \mathrm{kg})$, cálcio $(60-68 \mathrm{~g} / \mathrm{kg})$, fósforo $(18 \mathrm{~g} / \mathrm{kg})$, enxofre $(8000 \mathrm{mg} / \mathrm{kg})$, sódio $(47 \mathrm{~g} / \mathrm{kg})$, cobalto $(2,30 \mathrm{mg} / \mathrm{kg})$, cobre $(200 \mathrm{mg} / \mathrm{kg})$, ferro $(150 \mathrm{mg} / \mathrm{kg})$, iodo $(10 \mathrm{mg} /$ $\mathrm{kg}$ ), manganês $(400 \mathrm{mg} / \mathrm{kg})$, selênio $(2,0 \mathrm{mg} / \mathrm{kg})$, zinco $(1000 \mathrm{mg} /$ $\mathrm{kg})$, vit. A (40.000UI $/ \mathrm{kg}$ ) e flúor $(180 \mathrm{mg} / \mathrm{kg})$. Onze animais pertenciam à fazenda localizada no município de São Mateus, e dois à fazenda situada no município de São Luís.

Os animais do estudo foram selecionados de acordo com a presença de sinais clínicos sugestivos de PTB. Em todos os animais foi realizada biópsia retal de acordo com metodologia descrita por Belo-Reis et al. (2015), para pesquisa de Map através de PCR em tempo real (qPCR) e Ziehl-Neelsen (ZN). Sete animais foram positivos para presença de Map e alocados no Grupo1, e os outros seis foram negativos e alocados no Grupo 2. Devido ao prognóstico ruim, todos os animais foram eutanasiados e necropsiados, conforme recomendações do Conselho Nacional de Controle de Experimentação Animal (CONCEA 2008). Durante as necropsias foram coletados fragmentos de diversos órgãos que foram fixados em formol a 10\% tamponado, e processados pelos métodos usuais para exame histológico. Amostras de cerca de $200 \mathrm{~g}$ do lobo caudal do fígado foram coletadas com uma faca de aço inoxidável e armazenadas em sacos plásticos, identificadas e congeladas a $-20^{\circ} \mathrm{C}$ até a realização das análises. Através do tecido hepático foram determinados os teores de cobre ( $\mathrm{Cu})$, zinco $(\mathrm{Zn})$ e ferro (Fe).

Dosagem de minerais. As amostras de fígado foram seccionadas em fatias finas utilizando-se navalhas limpas e de aço inoxidável, armazenadas em tubos de polipropileno de $50 \mathrm{~mL}$ e submetidas ao processo de liofilização. Para esse processo, as amostras foram congeladas a $-20^{\circ} \mathrm{C}$ acondicionadas em bandejas e colocadas em aparelho automatizado LIOTOP ${ }^{\circledR}$ (modelo L101), previamente ligado por um período de 10 minutos a uma temperatura de $-55^{\circ} \mathrm{C}$, as quais permaneceram por um período de $24 \mathrm{~h}$ para a secagem completa. Posteriormente, as amostras foram trituradas em grau e pistilo (Pinheiro et al. 2011).

Para a determinação dos minerais $\mathrm{Cu}, \mathrm{Zn}$ e Fe, as amostras trituradas foram pesadas entre 0,250 a $0,260 \mathrm{~g}$ e colocadas em tubo de digestão de Teflon (modelo Xpress). Em seguida foram adicionados $3 \mathrm{~mL}$ de ácido nítrico PA 65\% (QUIMEX), $1 \mathrm{~mL}$ de ácido clorídrico a $30 \%$ (MERCK) e $1 \mathrm{~mL}$ de peróxido de hidrogênio PA 30\% (BIOTEC); ficaram em repouso durante $2 \mathrm{~h}$ para uma pré-digestão e digeridas por 50 minutos em sistema fechado por radiação de micro-ondas 
(MARSXpress, CEM Corp. Matthews, NC, USA). Após a digestão, os minerais $\mathrm{Cu}, \mathrm{Zn}$ e Fe foram analisados pela técnica de espectrometria de emissão ótica com plasma induzido (ICP-OES) no equipamento ICP-OES (Vista-MPX CCD simultâneo, axial da VARIAN) em sistema de amostragem automático (SPS-5). 0 controle das condições operacionais do ICP-OES foi realizado com o software iTEVA. Os brancos analíticos foram preparados pelos mesmos procedimentos sem a adição das amostras de fígado (Nomura et al. 2005). As análises foram realizadas no Instituto Evandro Chagas (ICE).

Estatística. Os resultados foram submetidos à análise de variância em delineamento inteiramente casualizado e as médias comparadas pelo teste de Tukey (SAS 2003).

\section{RESULTADOS}

Na fazenda localizada no município de São Mateus, MA, verificou-se que aproximadamente $70 \%$ das pastagens eram em terra firme composta por Brachiaria spp. (sinonímia Urochloa) e 30\% em região de várzea composta por pastagens nativas. No ambiente de terra firme as fontes de água eram bebedouros, e na região de várzea os animais bebiam nos lagos formados durante o período de chuva. Na fazenda no município de São Luís as pastagens eram em terra firme compostas por Brachiaria spp. (Sinonímia Urochloa). Em ambas as fazendas a suplementação protéico-energética era ofertada em cochos descobertos e a oferta não era continua ao longo do ano; no período de maior estiagem era ofertado somente sal proteinado.

O quadro clínico apresentado pelos búfalos nas duas localidades caracterizava-se por estado nutricional regular a ruim, diarreia líquida a semi-líquida, desidratação, edema submandibular (Fig.1A-B), anestro prolongado, mastites e verminose gastrintestinal. Os animais permaneciam longos períodos dentro dos lagos e quando eram estimulados a se locomover faziam de forma lenta.

Os sete búfalos positivos para detecção de Map (Grupo 1) apresentaram achados macroscópicos compatíveis com PTB, tais como aumento de linfonodos mesentéricos, mucosa do intestino delgado e grosso espessada, irregular, de aspecto reticulado e com dobras transversais evidentes. Observaram-se ainda áreas espessadas em torno da válvula íleocecal, vasos linfáticos evidentes e áreas esbranquiçadas na superfície de corte dos linfonodos mesentéricos (Fig.2). Foi evidenciado também que esses animais tinham linfonodos mesentéricos com áreas de coloração acastanhada sugestiva de hemossiderose (Fig.2). Adicionalmente, no

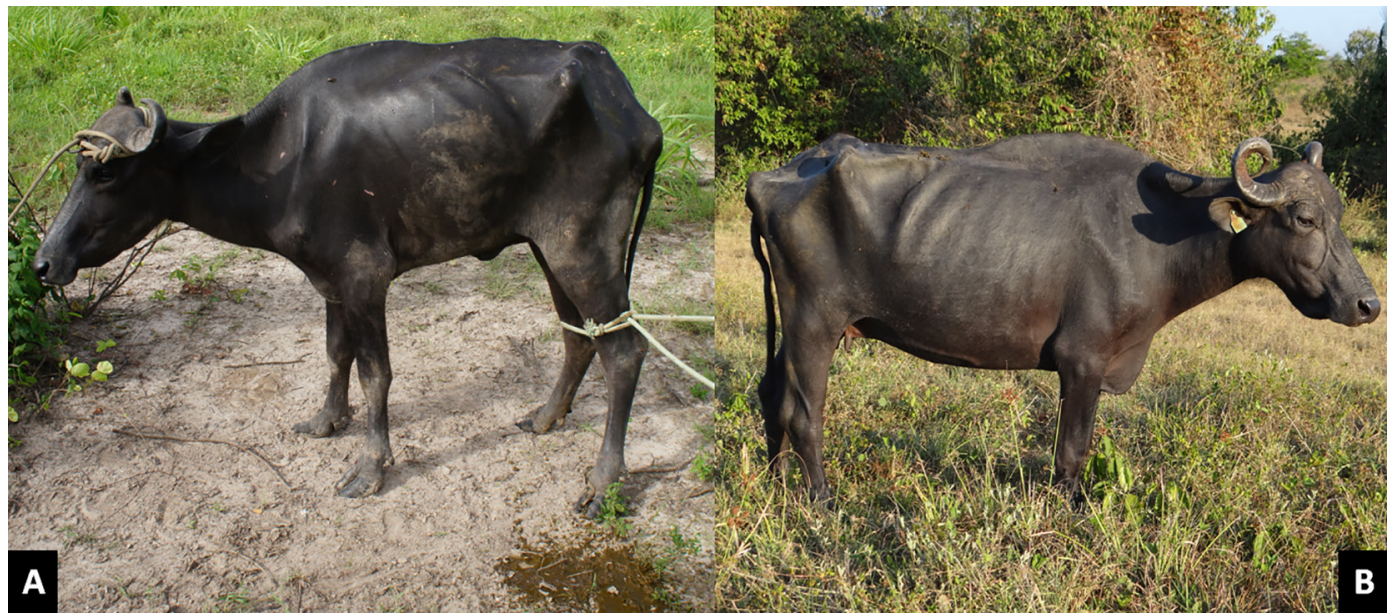

Fig.1. (A) Búfalo 3, positivo para paratuberculose, com escore corporal 2 e diarreia. (B) Búfalo 13 negativo para paratuberculose, com escore 2 e edema submandibular.

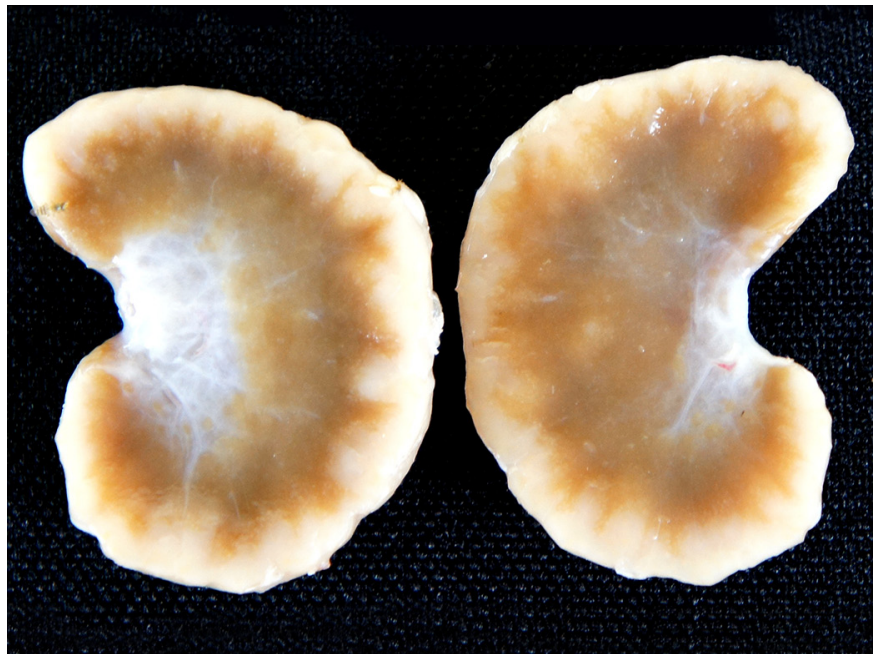

Fig.2. Linfonodos mesentéricos do Búfalo 3 de cor marrom com áreas esbranquiçadas na superfície de corte.

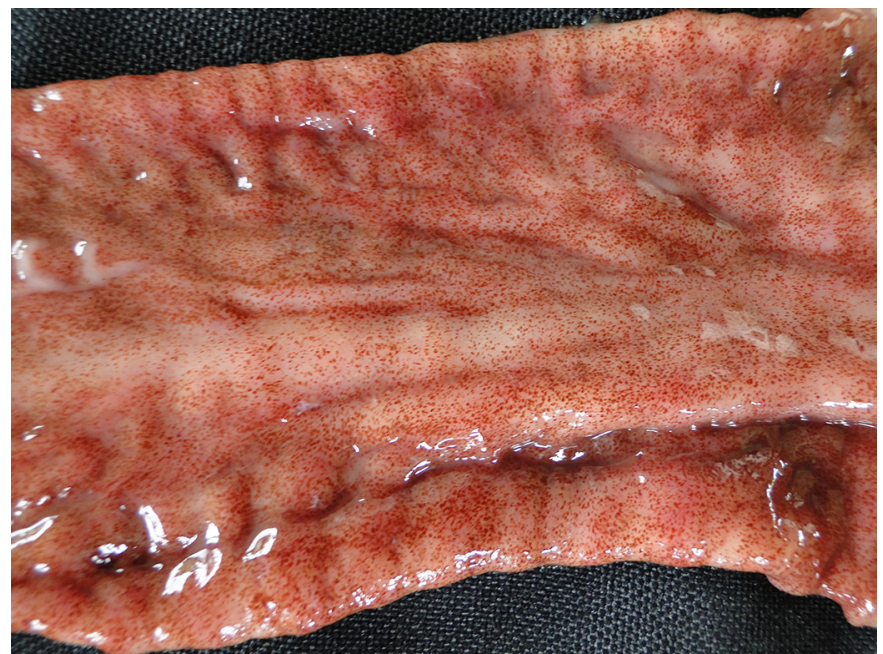

Fig.3. Pequenos pontos marrons distribuídos difusamente na mucosa intestinal do Búfalo 3, sugestivo de hemossiderose. 
Búfalo 3 foram observados pequenos pontos difusos de cor marrom na mucosa do intestino delgado (Fig.3), também sugestivos de hemossiderose. No Grupo 2 apenas três animais (Búfalas 8, 9 e 10) apresentaram linfonodos mesentéricos de coloração castanha escura.

Nos sete búfalos com PTB os exames histopatológicos revelaram infiltrado inflamatório granulomatoso rico em células gigantes na mucosa e infiltrado mononuclear na submucosa do intestino delgado. Nos linfonodos mesentéricos foram observadas células epitelioides e células gigantes na região cortical e medular. Os fragmentos de intestino e linfonodos mesentéricos apresentaram bacilos álcool-ácido resistentes (BAARs) pela coloração de ZN. Adicionalmente observou-se hemossiderosse moderada no baço e linfonodos mesentéricos.

Na qPCR foram positivos para Map os Búfalos 1, 2, 3, 5, 6 e 7 em fragmentos do íleo e linfonodos mesentéricos, e o Búfalo 4 foi positivo em fragmento do íleo e negativo em fragmento do linfonodo mesentérico. Os valores individuais, médias e desvio padrão dos teores de $\mathrm{Cu}$ e $\mathrm{Zn}$ no fígado dos búfalos avaliados com e sem paratuberculose estão apresentados no Quadro 1. Houve diferença estatística $(\mathrm{P}<0,5)$ entre os grupos, dos teores hepáticos dos três minerais avaliados.

\section{Quadro 1. Representação dos valores, médias e desvio padrão dos teores de cobre (Cu), zinco ( $\mathrm{Zn}$ ) e ferro (Fe) nos búfalos positivos e negativos para paratuberculose}

\begin{tabular}{|c|c|c|c|}
\hline Identificação & Cobre (ppm) & Zinco (ppm) & Ferro (ppm) \\
\hline \multicolumn{4}{|c|}{ Búfalos com paratuberculose } \\
\hline Búfalo 1 & 69,1 & 69,3 & 593,1 \\
\hline Búfalo 2 & 17,6 & 64,4 & 803,5 \\
\hline Búfalo 3 & 11,7 & 74,1 & 1285,4 \\
\hline Búfalo 4 & 11,6 & 43,4 & 689,6 \\
\hline Búfalo 5 & 8,0 & 54,7 & 686,8 \\
\hline Búfalo 6 & 5,5 & 80,6 & 800,6 \\
\hline Búfalo 7 & 3,0 & 93,9 & 1043,3 \\
\hline Média $^{1}$ & $18,1 \mathrm{a}$ & $68,6 a$ & $843,2 a$ \\
\hline Desvio padrão & \pm 23 & $\pm 16,7$ & $\pm 241,4$ \\
\hline Valores de referência ${ }^{2}$ & $<100$ & $<100$ & $181-380$ \\
\hline \multicolumn{4}{|c|}{ Búfalos negativos } \\
\hline Búfalo 8 & 88,7 & 197,3 & 795,5 \\
\hline Búfalo 9 & 136,6 & 113,0 & 1162,9 \\
\hline Búfalo 10 & 125,4 & 68,1 & 478,6 \\
\hline Búfalo 11 & 56,4 & 65,8 & 316,2 \\
\hline Búfalo 12 & 95,1 & 140,8 & 484,3 \\
\hline Búfalo 13 & 179,9 & 75,0 & 781,8 \\
\hline Média $^{1}$ & $113,7 \mathrm{~b}$ & $110,0 b$ & $669,9 b$ \\
\hline Desvio padrão & $\pm 43,1$ & $\pm 52,0$ & $\pm 305,8$ \\
\hline Valores de referência ${ }^{2}$ & $<100$ & $<100$ & $181-380$ \\
\hline Coeficiente de variação & 19 & 21 & 152 \\
\hline Valor de P & 0,003 & 0,071 & 0,277 \\
\hline
\end{tabular}

${ }^{1}$ Médias com letras diferentes na vertical diferem estatisticamente entre si pelo teste de Tukey em $5 \%$ de probabilidade. ${ }^{2}$ Underwood (1977).

Os teores dos microminerais $\mathrm{Cu}$ e $\mathrm{Zn}$ no fígado dos búfalos com paratuberculose (Grupo 1) apresentaram-se abaixo do normal; os teores de Fe em todos os búfalos foram superiores aos valores de referência. Quando se analisa as médias verifica-se que os teores de cobre estão extremamente baixos e os teores de zinco moderadamente baixos. Já a média dos teores de Fe foi mais de duas vezes superior aos teores normais (Quadro 1).
Nos búfalos sem paratuberculose (Grupo 2), 50\% (3/6) apresentam teores de $\mathrm{Cu}$ considerados como subdeficientes e quando se analisa a média obtida pelos seis búfalos verifica-se que os teores encontram-se acima de 100ppm, considerados no limite de normalidade. Achado semelhante foi obtido com o Zn onde também 50\% (3/6) apresentaram teores abaixo de $100 \mathrm{ppm}$, considerados também como subdeficientes. Quando se considera a média dos teores de Zn dos seis animais, esta ficou acima de 100ppm, também considerada no limite de normalidade (Quadro 1).

\section{DISCUSSÃO}

Como demonstrado no presente estudo não podemos basear o diagnóstico da PTB apenas nos sinais clínicos, uma vez que o emagrecimento progressivo acompanhado de diarreia pode estar presente em outras enfermidades como nas parasitoses, nas deficiências nutricionais e em outras doenças infecciosas bacterianas ou virais (Yamasaki et al. 2010, 2013). Apesar de 53,8\% (7/13) dos animais serem positivos para PTB, para a confirmação do diagnóstico existe a necessidade da obtenção de dados epidemiológicos sobre o status da enfermidade em um rebanho ou em uma região, e da realização de exames complementares. Sweeney (1996) estimou que para cada caso clínico confirmado de PTB existam 15 a 25 animais subclínicos. Baseado nesta estimativa pressupõe-se que as propriedades estudadas apresentam uma situação crítica quanto ao número de animais contaminados no rebanho.

Neste estudo, os búfalos com PTB, além das lesões típicas da enfermidade apresentaram, concomitantemente, lesões compatíveis com a deficiência de $\mathrm{Cu}$, que posteriormente foi confirmada por meio da histopatologia e da dosagem do elemento no fígado. Nos animais negativos os achados de necropsia foram compatíveis apenas com deficiência de energia e proteína.

A média dos teores de $\mathrm{Cu}$ no fígado das búfalas com PTB foi 18,0 ppm e para os animais negativos $113,7 \mathrm{ppm}$. Segundo Underwood (1977) valores de $\mathrm{Cu}$ em fígado entre zero e 50ppm da matéria seca indicam deficiência, de 50 a 100ppm, subdeficiência, e níveis acima de 100ppm são adequados. Baseando-se nesses dados entende-se que nos búfalos do presente estudo a PTB agravou o quadro de deficiência deste mineral. Como os animais negativos do Grupo 2 eram criados juntos com os animais positivos do Grupo 1, e não apresentaram deficiência ou apresentaram subdeficiência deste elemento, isso demonstra que a PTB pode reduzir os níveis de $\mathrm{Cu}$, e levar a quadros de subdeficiência ou de deficiência. Como a absorção do Cu ocorre no intestino (Carvalho et al. 2003) a enterite granulomatosa presente na PTB contribui para a redução da absorção deste mineral.

A média dos teores de Zn nos animais do Grupo 1 foi 68,6ppm e no Grupo 2 de 110,0ppm. Segundo Underwood (1977), valores de Zn no fígado menores que 100ppm indicam deficiência e valores acima de 101ppm são considerados normais. Neste estudo ficou demonstrado que os animais com PTB apresentaram níveis de $\mathrm{Zn}$ abaixo dos considerados normais. Nos búfalos com PTB não foram observadas manifestações clínicas da deficiência de Zn, pos- 
sivelmente por se tratar de uma deficiência de zinco marginal. Tokarnia et al. (2010) estudaram a deficiência de Zn e concluíram que provavelmente em algumas regiões, as quantidades de $\mathrm{Zn}$, mesmo baixas, ainda seriam suficientes para satisfazer as exigências dos animais.

Conforme Underwood \& Suttle (1999) as deficiências de Cu e Zn têm influência direta na resposta imune. Como a concentração de $\mathrm{Cu}$ e $\mathrm{Zn}$ nos búfalos do Grupo 1 foram baixas, possivelmente a resposta imunológica já estava comprometida e consequentemente, esse pode ser mais um fator que levou ao agravamento do quadro clínico da PTB e predispôs à maior susceptibilidade a outras infecções.

A média dos teores de Fe nos búfalos com PTB foi $843,2 \mathrm{ppm}$ e nos búfalos negativos 669,9ppm. Segundo Underwood (1977) teores de Fe entre 181-380ppm são considerados normais e valores acima de 381ppm aumentados. No presente estudo os teores de Fe estavam aumentados tanto nos animais do Grupo 1 quanto nos do Grupo 2, sendo que nos búfalos com PTB, esses valores foram aproximadamente 20\% maiores quando comparados aos do Grupo 2 (Búfalos sem paratuberculose). É importante salientar que o excesso de ferro nos tecidos, principalmente no fígado, pode significar apenas hemossiderose, que ocorre na deficiência de $\mathrm{Cu}$, e que foi observada nos búfalos do Grupo 1 deste estudo. Porém, como os teores de Fe estavam aumentados tanto nos animais deficientes como nos subdeficientes em $\mathrm{Cu}$, infere-se que esses altos teores de Fe sejam oriundos da forragem e da mistura mineral ofertada aos animais.

De acordo com Underwood \& Suttle (1999) o Fe é considerado um antagonista do $\mathrm{Cu}$ e interfere na sua absorção. Lounis et al. (2001) afirmam que uma dieta rica em Fe pode aumentar o número de Map e assim agravar o quadro clínico de PTB nos animais. Desta forma o excesso de Fe nos animais positivos poderia ter causado pelo menos dois efeitos deletérios, o primeiro associado à antagonização da absorção do $\mathrm{Cu}$ e segundo, poderia ter servido como substrato para o crescimento e multiplicação de Map e assim favorecer o agravamento do quadro clínico de PTB nos búfalos.

Com relação ao quadro de emagrecimento observado nos animais sem paratuberculose (Grupo 2), pode ser justificado pela baixa oferta de alimentos no período de estiagem, quando foram realizadas as visitas técnicas às propriedades. Outro fator que poderia contribuir seria os baixos teores de alguns minerais, causando uma deficiência subclínica, como foi observado em alguns búfalos sem paratuberculose (Búfalos 8, 11 e 12). De acordo com Tokarnia et al. (2010) as deficiências de energia e proteína são as que causam os maiores prejuízos.

\section{CONCLUSÃO}

Baseado nos achados clínico-patológicos e nas dosagens de minerais realizadas no fígado dos búfalos deste estudo, conclui-se que a paratuberculose pode induzir quadros de deficiência mineral ou agravar quadros de subdeficiência, com consequente piora do quadro clínico da paratuberculose.
Agradecimentos.- Ao Conselho Nacional de Desenvolvimento Científico e Tecnológico (CNPq) e à Coordenação de Aperfeiçoamento de Pessoal de Nível Superior (CAPES) pela concessão de bolsa, ao Instituto Evandro Chagas pelo apoio à realização das dosagens dos minerais e à Dra Simone Frotas dos Reis pelo apoio com as análises estatísticas.

\section{REFERÊNCIAS}

Belo Reis A.S., Brito M.F., Bezerra Jr P.S., Fonseca Jr A.A., Ubiali D.G., Mota R.A., Leite R.C. \& Barbosa J.D. 2015. Diagnóstico de paratuberculose por biópsia retal em búfalos. Pesq. Vet. Bras. 35(10):823-828.

Carvalho F.A.N., Barbosa F.A. \& McDowel L.R. 2003. Nutrição de Bovinos a Pasto. Papelform, Belo Horizonte. 438p.

Chiodini R.J. \& Van Kruiningen H.J. \& Merkal R.S. 1984. Ruminant paratuberculosis (Johne's disease): the current status and future prospects. Cornell Vet. 74:218-262.

Clarke C.J. 1997. The pathology and patogenesis of paratuberculosis in ruminants and other species. J. Comp. Pathol. 116:217-261.

CONCEA 2008. Conselho Nacional de Controle de Experimentação Animal, V do Art. 5o da Lei no.11.794, de 8 de outubro de 2008.

Lamb G.C., Brown D.R., Larson J.E., Dahlen C.R., Dilorenzo N., Arthington J.D. \& Dicostanzo A. 2008. Effect of organic or inorganic trace mineral supplementation on follicular response, ovulation, and embryo production in superovulated Angus heifers. Anim. Reprod. Sci. 106(3/4):221231.

Lounis N., Truffot-Pernot C., Grosset J., Gordeuk V.R. \& Boelaert J.R. 2001. Iron and Mycobacterium tuberculosis infection. J. Clin. Virol. 20:123-126.

Lungton I.W. 2004. Review of possible links between the clinical expression of paratuberculosis and deficiency of macro and micronutrients. Aust. Vet J. 82(8):490-496.

Mota R.A., Peixoto P.V., Yamasaki E.M., Medeiros E.S., Costa M.M., Peixoto R.M. \& Brito M.F. 2010. Ocorrência de paratuberculose em búfalos ( $\mathrm{Bu}$ balus bubalis) em Pernambuco. Pesq. Vet. Bras. 30(3):237-242.

Nomura C.S., Silva C.S., Nogueira A.R.A. \& Oliveira P.V. 2005. Bovine liver sample preparation and micro-homogeneity study for $\mathrm{Cu}$ and $\mathrm{Zn}$ determination by solid sampling electrothermal atomic absorption spectrometry. Spectrochimica Acta B. 60:673-680.

Pinheiro C.P., Bomjardim H.A., Andrade S.J.T., Faial K.C.F., Oliveira C.M.C. \& Barbosa J.D. 2011. Níveis de fósforo, cobre, cobalto e zinco em bubalinos (Bubalus bubalis) na Ilha de Marajó, Estado do Pará. Pesq. Vet. Bras. 31(3):193-198.

Paolicchi F., Perea J., Cseh S. \& Morsella C. 2013. Relationship between paratuberculosis and the microelements copper, zinc, iron, selenium and molybdenum in beef cattle. Braz. J. Microbiol. 44(1):153-160.

SAS Institute Inc. 2003. Statistical analysis system. Release 9.1. (Software). Cary. USA.

Sweeney R.W. 1996. Transmission of paratuberculosis. Vet. Clin. N. Am. Food A. 12(12):305-312.

Tokarnia C.H., Peixoto P.V., Barbosa J.D., Brito M.F. \& Döbereiner J. 2010. Deficiências Minerais em Animais de Produção. Helianthus, Rio de Janeiro, 191p.

Underwood E.J. 1977. Trace Elements in Human and Animals Nutrition. 4th ed. Academic Press, New York. 545p.

Underwood E.J. \& Suttle N.F. 1999. The Mineral Nutrition of Livestock. 3rd ed. CABI Publishing, Wallingford. 614p.

Wilde D. 2006. Influence of macro and micro minerals in the peri-parturient period on fertility in dairy cattle. Anim. Reprod. Sci. 96:240-249.

Yamasaki E.M., Brito M.F., Mota R.A., McIntosh D. \& Tokarnia C.H. 2013. Paratuberculose em ruminantes no Brasil. Pesq. Vet. Bras. 33(2):127-140.

Yamasaki E.M., Tokarnia C.H., Galvão A., Gomes M.J.P., Chies J.A.B., Veit T.D., Aragão A.P. \& Brito M.F. 2010. Aspectos clínicos patológicos e controle da paratuberculose em rebanho bovino leiteiro. Pesq. Vet. Bras. 30(11):921-932. 